Western University

Scholarship@Western

FIMS Publications

Information \& Media Studies (FIMS) Faculty

2017

Visual Research in LIS: Complementary and Alternative Methods

Angela Pollak

The University of Western Ontario, apollak@uwo.ca

Follow this and additional works at: https://ir.lib.uwo.ca/fimspub

Part of the Library and Information Science Commons

Citation of this paper: 


\title{
Visual Research in LIS: Complementary and Alternative Methods
}

(Accepted, scheduled for publication in Library and Information Science Research, Vol 29, Iss 2) Pre-print version. Full published version available free until June 3, 2017 at https://authors.elsevier.com/a/1UtX12eSLIOtJ2

Angela Pollak

University of Western Ontario

\begin{abstract}
:
Although visual methods are emerging as a valuable and versatile tool in qualitative social studies research, confusion around terminology, options, and best practices persists.

Consequently, LIS scholars who wish to employ innovative visual approaches in their research face barriers to discovering and deciding which visual options best suit their goals. Based on a review of the literature, this article identifies and describes the scope of participatory and nonparticipatory visual methods currently in use in the social sciences, with particular attention paid to LIS contexts. While visual methods bring clear benefits to qualitative research in terms of data quality, modes of expression, and alternate perspectives, challenges remain, including logistic issues of implementing visual study designs and ethical considerations.
\end{abstract}




\section{Introduction}

Metaphorically "linking the human eye with the acquisition of knowledge is a practice as old, if not older, than the philosophy of Plato" due in large part to the amount of information we process visually (Wilder, 2009). When the first camera was introduced to the public in 1839 by the British Royal Society, researchers were quick to appreciate its scientific advantages, which primarily included the ability to reliably capture and preserve objective, factual data (Wilder, 2009).

Since that time, the use of imagery in research has straddled the line between data and decoration. While the reliability of quantitative data provided by scientific imaging has proven revolutionary in fields such as engineering and medicine (for example, satellite imagery or CAT scans), its adoption in qualitative social scientific disciplines, including Library and Information Science (LIS), has been slower and less dramatic due to the often exploratory, highly social, subjective and contextual nature of the data they represent. Consequently images that support or represent textual or numerical information (such as charts, graphs), and which are designed to narrow or hone our understanding of the topic under study are still privileged. Visual methods that introduce degrees of variability and uncertainty to text-based inquiry and reporting remain less frequently employed, despite complex, unique, valuable features and emic perspectives (Julien, Given, \& Opryshko, 2013) that can be captured in no other way.

Proliferation of personal electronic communication devices, however, increasingly means that citizens and researchers in both developing countries and in the western world not only have access to still image and video camera technology but also to the knowledge of how to use it. It should come as no surprise then, that LIS, which is itself interdisciplinary, should "continue to pursue research methodologies that are themselves adaptive and open to the continuing evolution of human culture" (Horn, 1998).

This literature review offers a better understanding of what constitutes visual methods, how visual data are being applied in interdisciplinary social scientific research, and insight into its potential for use in LIS contexts. As a primer, it maps the range of terminology associated with visual methods, and contemporary usage of this methodology as viewed primarily through serial publications. It is most likely to appeal to researchers who are new to or curious about visual methods.

\section{Why Visual Methods?}

Visual research is broadly understood to include collecting, producing, organizing and interpreting imagery in all its various forms for research purposes (Prosser, 2007). Imagery can originate from a multitude of sources, including photographs, film, and other forms of visual art such as drawings or sculpture. Beyond a basic definition of what visual means, however, there is little consensus among researchers about what the options are, or when, how or why to use them.

Hartel and Thomson point out terminological inconsistencies, indicating that visual methods, visual research, and visual approaches are essentially the same thing, and can be both methodology, thus "steer[ing] an entire research design", and "one data-gathering technique [or method] within a multimethod study"(J. K. Hartel \& Thomson, 2011). Complicating matters, multiple varieties of visual methods can be combined within a single study, and subsequently given independent names to describe the use of a particular group of techniques.

Further, Julien, Given and Opryshko (2013) suggest that "few scholars publish meta-level discussions of their methodological approaches, which could guide new research practices within the field." This is 
particularly so with visual research, where the current depth of methodological description is best described as inconsistent.

Finally, the metaphor of the camera as eye is as much about "the way knowledge is gathered with photography, and the way that knowledge is valued" (Wilder, 2009) as it is about the science behind mechanical reproduction. The viewpoint from which the camera collects its images is central to our growing understanding of when, where, and why visual methods are useful and appropriate in qualitative research in all disciplines, including LIS.

Consequently, LIS researchers who wish to employ innovative visual approaches face additional obstacles when discovering visual research options and deciding which ones best suit their goals. There is a need to understand the breadth of terminology attached to different visual methods of data collection, best practices for executing the different methods, as well as the subtleties of how methodology influences the data itself, the interpretation, and the diffusion of research results. The following guiding points served as the basis for the search:

- What are the variety of available visual methods currently in use in social science disciplines? How are they named? How are they defined?

- Who has used visual methods, in what contexts, for what purpose?

- What are the advantages, limitations, and ethical considerations associated with pursuing visual research?

\subsection{Scope of Discussion}

This article serves as a practical guide to understanding how visual methods are being used in research today as described in contemporary periodical publications. Readers interested in discovering the depth and variety of discussions related to the theoretical underpinnings of visual methods are directed to the following predominantly monograph sources which can provide more detailed information on the origins and history of visual methods in anthropology and sociology, discussions of ontological constructions of images and interpretative perspectives, as well as more advanced discussions of ethics.

- Widely seen as a pioneer of visual methodology, John Collier Jr. published "Visual Anthropology: Photography as a Research Method" which he later revised in collaboration with Malcolm Collier (Collier, 1967; Collier \& Collier, 1986).

- Similarly, the work of Jean Rouch in pioneering ethnofiction has been instrumental in developing awareness of film as a methodological tool. Primary sources created by Rouch are available in film format (Documentary Education Resources, 2016). There are also a wide variety of secondary sources available about Rouch and his impressive body of work (Documentary Educational Resources, 2016; Eaton, 1979; Rouch \& Feld, 2003; Stoller, 1992).

- Jon Wagner's edited book "Images of information: Still photography in the social sciences" includes sixteen chapters written by leaders in the field of visual anthropology and visual sociology, including pieces by John Collier, Douglas Harper, and himself (Wagner, 1979).

- David A. Harper published a number of pieces discussing visual methods, including a chapter in Denzen and Lincoln's Handbook of Qualitative Research (Harper, 1993)

- More recently, a number of reference books describing how to study and analyze visual artifacts and culture have gained a following, especially among students and researchers new to the field of visual anthropology and visual sociology (Banks, 2001; Banks \& Ruby, 2011; Rose, 2012).

- Around the same time frame, Prosser \& Loxley (who are well known for working among populations facing disabilities) produced a sizeable paper designed to orient new researchers to the use of visual methods of data collection (Prosser \& Loxley, 2008). 
- Pauwels presents a refined analytical framework from which to examine visual methods (Pauwels, 2010, 2015).

- The abstract of a panel discussion presented at the 2012 ASIST conference discussing examples of visual methodologies in use in LIS research may be of interest (J. Hartel, Lundh, Sonnenwald, \& Foster, 2012).

- Finally, Sandra Weber and Claudia Mitchell have explored innovative and evolving ways of using emerging technology, artefacts and artistic formats in connection with the Image and Identity Research Collective (Weber, 1993; Weber \& Mitchell, 2016).

Although an entirely comprehensive list of monographic publications is beyond the scope of this paper, these references provide at a minimum a starting point from which to engage further with the literature surrounding visual methods.

\section{Literature Review}

The literature review was conducted during the fall of 2013 for the purposes of supporting a larger study, and updated again in 2016. Databases primarily in the disciplines of LIS, social sciences, and humanities were examined using combinations of keywords (for example, visual*, photo*, imag*, video*, film*, elicitation, graphic, art, sensor*). Based on the assumption that the most relevant and descriptive studies would be the ones where authors themselves elevated the use of visual methodology to include mention in title or abstract, initial searching was generally limited to these fields. Although artistic methods (including drawing, diagramming, sculpture or map-making for example) are mentioned in this review, emphasis is placed on photographic or film-based visual methods.

From there, searching occurred in an iterative process until saturation was reached. As new terminology appeared, new searches were conducted using expanded keywords (for example, photo novel/novella, auto-driving, domestic photography) and alternate fields. Databases, journals and articles that produced relevant results were examined in more detail, including associated controlled vocabulary tags and citations. Publication histories for authors who established themselves as visual methods experts were also examined more closely, as were selective monograph items.

While this net captures many articles reflecting the use of visual methods, it is also subject to inherent limitations. In applying contemporary language to searches, items may have been excluded from this review because authors either chose to use alternate vocabulary to describe their methodology, or because they did not fully describe or emphasize their methodology despite the fact that elements of visual data collection and analysis were present. Although it may be argued that this is a flaw in the search process, I believe it also points to other important dynamics and challenges worth highlighting that are present in the contemporary estuary of visual methodologies. The presence and absence of specific studies one might expect to see in the following lists highlights the topography and growing pains associated with the slow process of integrating interdisciplinary research methods into LIS research design and reporting, including the consequences of naturally occurring inconsistent terminological usage. As researchers explore, experiment and extend these methodologies, one might expect the vocabulary to normalize over time. This is not always the case. Further contributing to the challenge, pieces may not be recognized or described as methodologically significant when initially published, but may retrospectively be deemed landmark pieces in new or emerging contexts. Reinterpreting a piece as methodologically significant does little in practice to make it easier to find.

One of the most significant findings of this review, therefore, is that there is little "consensus about how [visual] methods should be used," (Cross, Kabel, \& Lysack, 2006), and even less consensus about the component parts of the methods, or even the names of the methods themselves. This complaint 
appeared repeatedly across disciplines and time periods. Some of this uncertainty arises as a result of the natural development of the method, and the ways in which "photovoice has been widely adapted to fit the particular needs of research and documentation projects" (Catalani \& Minkler, 2010). Further, "there is considerable debate and disagreement about the relative merits of different approaches to the use of photography in research" (Hall, 2009).

Researchers drew on many different disciplinary traditions for their study designs, from sociology and anthropology, to health sciences, to visual or performing arts, to geography just to name a few. Articles often lacked explicit method definitions, tending instead to focus on either descriptions of the procedures used to collect the photographs, or the theory justifying the method. In many cases, it was left up to the reader to identify one or more of methodology, process, or assumptions. Consequently, despite some shared characteristics, discernible standards were rare between studies and disciplines. Patterns of evolution in method were reserved mainly for sequential investigations carried out by the same researcher, presumably due to increased experience with the chosen method over an extended period of time.

The primary challenge of parsing visual research methods, then, appears to be a lack of overarching framework in which to situate individual methods. Confusion arises about how to place multiple visual methods in relation to science, art, individual disciplines, each other, the researcher, the participants, and the broader social context. This is not to say that visual approaches individually or collectively are lacking credibility. Case (2007) advocates that "methods offer us a choice of plans for asking questions and finding answers to them." Weingand (1993) notes that methods need to be responsive to the population and problem under examination, and that "certain problems and clients will respond to one type of approach, while other problems and clients may be better suited to another strategy." Visual methods therefore can be seen to provide an array of valuable, appropriate, and currently underutilized choices in terms of data collection and reporting methods not only in the social sciences generally, but specifically in LIS research.

\section{Findings - A Framework for Visual Methods}

If we consider the idea once again of camera as eye, and how images are used to gather, create and embody knowledge, authorial perspective becomes the primary dividing line between varieties of visual research leaving essentially into two categories. Depending on who the creator of the image is, visual methods will be either non-participatory (etic) or participatory (emic).

Following is a synthesized description of the characteristics of each category of visual method, followed by explanations of individual methods based on those characteristics. As with all discussions of visual methods that have come before, this description is necessarily incomplete. Visual methods are evolving across disciplines, and our understanding and use of visual methods will continue to evolve both in and outside of Library and Information Science as well. 


\begin{tabular}{|c|c|c|c|c|c|c|c|c|c|c|}
\hline \multirow[b]{2}{*}{ Name of Visual Method } & \multirow[b]{2}{*}{ Data Source } & \multicolumn{2}{|l|}{ Type } & \multicolumn{2}{|c|}{ Usage } & \multicolumn{3}{|c|}{ Creator } & \multicolumn{2}{|c|}{ Interpreter } \\
\hline & & 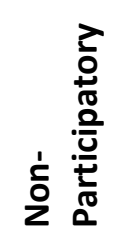 & $\begin{array}{l}\frac{2}{0} \\
\frac{0}{\pi} \\
\frac{0}{0} \\
\frac{0}{2} \\
\frac{1}{\pi} \\
0\end{array}$ & 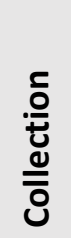 & 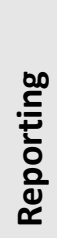 & 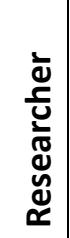 & 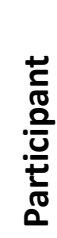 & 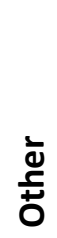 & 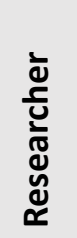 & 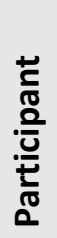 \\
\hline $\begin{array}{l}\text { Photography, Videography, } \\
\text { Filmography, Photo Survey, Photo } \\
\text { Inventory }\end{array}$ & Images & $\checkmark$ & & $\checkmark$ & & $\checkmark$ & & & $\checkmark$ & \\
\hline Repeat Photography & Images & $\checkmark$ & & $\checkmark$ & $\checkmark$ & $\checkmark$ & & $\checkmark$ & $\checkmark$ & \\
\hline $\begin{array}{l}\text { Salvage Photography, Domestic } \\
\text { Photography, Ordinary } \\
\text { photography }\end{array}$ & Images & $\checkmark$ & & $\checkmark$ & & & $\checkmark$ & $\checkmark$ & $\checkmark$ & $\checkmark$ \\
\hline $\begin{array}{l}\text { Documentary Photography, } \\
\text { Documentary Filmography }\end{array}$ & Images, film & $\checkmark$ & & $\checkmark$ & $\checkmark$ & $\checkmark$ & & & $\checkmark$ & \\
\hline $\begin{array}{l}\text { Elicitation (Photo, Film, Graphic, } \\
\text { Art), Auto-driving }\end{array}$ & $\begin{array}{l}\text { Verbal } \\
\text { explanation } \\
\text { based on } \\
\text { images }\end{array}$ & & $\checkmark$ & $\checkmark$ & & & $\checkmark$ & $\checkmark$ & $\checkmark$ & $\checkmark$ \\
\hline $\begin{array}{l}\text { Photovoice, Photo-projective, } \\
\text { Photo-interviewing, Photo-diary, } \\
\text { Auto-photography, Reflexive } \\
\text { photography, Photo novel/novella, } \\
\text { photo-essay, photo-narrative }\end{array}$ & $\begin{array}{l}\text { Images } \\
\text { together } \\
\text { with verbal } \\
\text { explanation }\end{array}$ & & $\checkmark$ & $\checkmark$ & $\checkmark$ & & $\checkmark$ & $\checkmark$ & $\checkmark$ & $\checkmark$ \\
\hline $\begin{array}{l}\text { Image, art, sensory, multi-sensory } \\
\text { methods }\end{array}$ & $\begin{array}{l}\text { Artistic } \\
\text { images, } \\
\text { Verbal } \\
\text { explanation } \\
\text { based on } \\
\text { images }\end{array}$ & & $\checkmark$ & $\checkmark$ & $\checkmark$ & & $\checkmark$ & $\checkmark$ & $\checkmark$ & $\checkmark$ \\
\hline
\end{tabular}

Figure 1 - List of Visual Methods and Features

Participatory and non-participatory types of visual data collection and reporting, highlighting who creates the data, who interprets it, and how it is reported. 


\subsection{Non-Participatory Visual Methods}

Non-participatory visual methods have a long history in scientific research due in large part to the epistemological belief that the camera is a tool of realism and can capture physical truths with objectivity. Often involving purposes related to the content of images (record-keeping or factual description for example), non-participatory visual images are traditionally intentionally captured by the researcher under varying degrees of control for the purposes of one particularly scientific study. Both creation and interpretation remain under the control of the researcher at all times.

Under some circumstances (such as in the case of archived images for example), images can be repurposed at a later time by third parties for different studies unrelated (or loosely related) to the original research for which they were obtained.

\subsubsection{Photography, Videography, Filmography, Photo Survey, Photo Inventory}

The researcher uses still or moving images to make a visual record of objects, people or locations under study. The value of images of this variety tend to be content-based. The purpose of photography is to document, describe or compare items under study; to provide evidence; to help prod the researcher's memory of field experiences; to immerse the researcher in the context under examination.

In library and information science, Jenna Hartel's (2006) dissertation on the hobby of gourmet cooking used still photography to document the information spaces of the hobby gourmet cook in a "photographic inventory." Marshall, Burns and Briden (2007) used photo-survey methods in a qualitative ethnographic examination of the information behaviors and activities of students at Rochester University Library. McKenzie and Davies (2012) collected photographs of tools people use to keep track of information in everyday life.

Interdisciplinary examples include Hall (2009), who describes photo-survey as one "element of the description of places studied" and notes that it is common practice in the work of human geography. Erim (2011) conducted a video-ethnography of the experience of dance.

Note that Moore et al. (2008) used the term photographic survey to describe the participatory visual photo-elicitation method. Huck, Al and Raithi (2011) used documentary photography in a study of knowledge management needs in a volunteer-operated bicycle repair shop in Canada. Unfortunately, the method description stated simply "photographs were taken of the workshop." In this regard, it seems Huck's definition of documentary photography is aligned more closely with the above description of photography.

\subsubsection{Repeat Photography}

Repeat photography Involves taking identical photographs (for example, in the same location from the same perspective) at different times. The purpose is to monitor physical changes and transformations in settings over time; "to construct knowledge about place, environment and people's relationship with it" by creating "a new way of seeing that allows the viewer to know the world differently" (Smith, 2007); to allow contemporary researchers to share location-based experiences with historical researchers.

Pollak (2015) included an example of repeat photography in her analysis of a rural community. There is potential for use of this method in exploring information spaces over extended periods of time.

Smith (2007) used repeat photography to conduct a study into the physical and cultural spaces at Waterton Lakes National Park in Alberta, Canada. Her literature review describes studies in the natural sciences examining glacial movement with this method dating back to the 1880 s. 
As described by Smith, this technique specifically makes use of salvage photography to compare current images to archival images retrospectively. It also has potential to be used longitudinally to compare images captured in current times to those that will be taken in the future.

\subsubsection{Salvage Photography, Domestic Photography, Ordinary photography}

The researcher collects pre-existing photographs that were likely created for reasons unrelated to the current research project. This can include images from personal collections, institutional collections, or archival collections. It could also include images published in the media or otherwise available publicly, for example postcard images of communities produced during the 1890-1990 time periods now available through deltiology clubs. The purpose is to "catalogue and order historical persons, objects, and actions, to document what happened during historical periods, to understand how people in the past viewed their world, and to analyze contemporary society by examining how we visualize our history" (Perlmutter, 1994). Images can also be used in combination with elicitation techniques to enrich the interview process with more detailed descriptions of historical people, places or events.

Pollak (2015) used salvage photography as an elicitation technique during the interview process to examine experiential information in a rural community in Northern Ontario.

Kuhn (2007) used salvaged personal photographs to examine cultural memory. Arreola and Burkhart (2010) used historic postcards to examine urban landscape change.

Note that David Perlmutter (1994) provides an excellent framework from which to examine the content of historical photographs.

\subsubsection{Documentary Photography, Documentary Filmography}

The researcher, who is often a photographer, uses images possibly accompanied by narrative descriptions to deliver a story, usually to a public audience. The delivery method is visual and can take many forms including book, video or public exhibit. Although control over the creation and interpretation of images rests with the creator of the image, this method of data collection exhibits a more artistic, social, ethnographic flavour. Results are intended to be shared with broader audiences and serve to educate people about a particular context. Documentary visual methods are often used in media applications. The purpose is to tell a story; to educate; to draw attention to an interesting or noteworthy context; to mobilize audiences to support a cause.

Julien and Hoffman (2008) used documentary photography in the context of investigating the role of public libraries in information literacy training.

For examples of documentary photography, see the works of Sebastião Salgado (1986) studying Central and South America, Ansel Adams (2006) documenting the Sierra Nevada, or Dorothea Lange (1969) who examined rural poverty in the west during the depression.

\subsection{Participatory Visual Methods}

Participatory visual methods involve the researcher commissioning images as part of the research project, with the task of creation assigned to a community of informants. Informants are given the tools and instruction on how to use them, and asked to photograph aspects of the subject under study in their environment. Interpretation can happen by researcher, participants, or both.

Participant-generated images are generally introduced for their contextual value, and allow the researcher to metaphorically see through the participants' eyes. Not surprisingly, data collection of this variety naturally leads to highly personalized, subjective data that might not otherwise be available to the researcher. Analysis usually goes beyond inventorying the content of images to discuss affective 
components and meaning. Although participatory visual methods are seen as a way of neutralizing to some extent the power differential that exists inherently between researcher and participant, or between the participants and other hegemonic institutions and cultures, it is generally understood that the researcher cannot be removed from the facilitation process entirely.

\subsubsection{Elicitation (Photo, Film, Graphic, Art), Auto-driving}

Based in part on principles of participatory communication, elicitation methods use images during the interview process to direct discussions. In general, visual elicitation methods can use images that originate from any number of different participatory and non-participatory sources. In the absence of specification, they are likely assumed to be participant-generated. The term auto-driving derives from the fact that the participant controls or drives this type of interview. The purpose is to invest people individually and collectively in the research process; to allow "a dynamic, interactional, and transformative process of dialogue between people, groups, and institutions" (Singhal, Harter, Chitnis, \& Sharma, 2007); to gain access to perspectives on the research topic that otherwise might be unavailable to the researcher; to improve participants' recollection; to enrich the quality of verbal descriptions; to equalize power imbalances inherent to the research process.

Haberl and Wortman (2012) used photo-elicitation methodology to study client perceptions of space at the Edmonton Public Library.

Pioneered in anthropology by John Collier Jr. (Collier \& Collier, 1986), and inspired in part by the works of Paulo Freire (Freire, 1993; Freire \& Faundez, 1989; Freire \& Freire, 1994, 1997), visual elicitation methods (see photovoice below) are often employed in an effort to empower disadvantaged communities for change.

\subsubsection{Photovoice, Photo-projective, Photo-interviewing, Photo-diary, Auto- photography, Reflexive photography, Photo novel/novella, photo-essay, photo-narrative}

A combination of elicitation and, specifically, participant-generated images, participants are charged with the responsibility of creating images that represent specific aspects of the subject under study. This method is generally followed by elicitation and discussion of the images during individual and/or group interviews. Wang and Redwood-Jones (2001) note that the participants' "familiarity with their surroundings gives community members a distinct advantage over professionals in their ability to move through the community, [and to] portray its strengths and concerns" visually. The purpose is to assess a community from the perspective of members; to communicate participant views to policy makers (Wang \& Redwood-Jones, 2001); the photo-projective method attempts to "understand the individual's internal mental world" based on their reflection and relationship with the external context illustrated in their photographs (Okamoto et al., 2006); to highlight and neutralize power and agency imbalances in research and policy (Wang \& Burris, 1997).

Gabridge et al. (Gabridge, Gaskell, \& Stout, 2008) reported on a study using photo-diaries to examine the information seeking behavior of 32 academic students at Massachusetts Institute of Technology. Keller (2012) used photo-diaries and photo-interviews to examine reading habits of undergraduate students. Julien, Given and Opryshko (2013) used a multi-method design, including photovoice, to "gather data to inform information literacy interventions at the undergraduate level based on students' authentic experiences."

Caroline Wang is a pioneer of photovoice/photo-novella in public health research examining rural women in China (Wang, Burris, \& Ping, 1996). Allen (2008) used the photo-diary method to examine agency in the representation of sexuality among New Zealand teenagers. Anthropologists Foster and 
Gibbons (2007) used photovoice in "Studying Students," an undergraduate research project conducted at the University of Rochester which included examining library usage.

Note that the broad term 'collaborative methods' are related to photovoice such that the researcher and participant share responsibility in different proportions for co-creating visual images. For example, the researcher may take the photographs under the direction of the participant (Hall, 2009). It can also include other mediums such as pictures, paintings or comics.

\subsubsection{Image/art/sensory/multi-sensory methods}

Art-based methods involve participants using sensory apparati (paper, pens, pencils, paint, modeling compound and so on) to create non-photographic visual images and objects (for example, diagrams, drawings, sculptures, paintings and so on). The use of participant-generated images and art "can involve reflecting upon inner revere, or dialogue, the experience of fleeting emotions, and very visceral embodied emotions can be stimulated by the different [tactile] qualities of the art materials" (Pink, Hogan, \& Bird, 2011). The purpose is to open possibilities for non-verbal ways of knowing and communicating (Bishop, 2006); to offer a different communication tool to researchers and participants who do not share a common language (Pink et al., 2011);

Denham (1993) used participant-generated drawings to examine how youth aged 9-14 understand the concept of computers. Sonnenwald developed a process for having students draw maps of their information horizons to understand information seeking behaviour of lower socio-economic students (Sonnenwald, Wildemuth, \& Harmon, 2001). Mair and Kierens reported on the use of the draw-andwrite technique in social research (Mair \& Kierans, 2007). Pink et al. (2011) used art-based methodology to explore women's experience of domestic violence. Umoquit et al conducted a multi-disciplinary systematic review of the use of diagrams as a data collection tool across thirteen different healthcare and non-healthcare indexes, specifically highlighting the need for standardized terminology with this specific data collection method (Umoquit, Tso, Burchett, \& Dobrow, 2011). And Hartel used an artsinformed method of data collection she called "iSquares" to learn about how graduate students in an LIS program define the term information (J. Hartel, 2014).

These methods reflect "a sensory turn stretching across the social sciences, humanities and arts practice" as well as "growing consideration of the role of all of the senses in the construction and representation of experience" and knowledge (Pink et al., 2011).

\section{Discussion}

\subsection{Advantages of Visual Methods}

The fact that visual methods of data collection are gaining in popularity across disciplines suggests that they present some unique advantages over traditional non-visual methods of qualitative data collection. It is reasonable to expect that these benefits can be achieved in Library and Information Science research as well. Although researchers have noted a wide variety of benefits, Meo, in her critique of photo-elicitation methods cautions that "not all [studies exhibit] all these advantages in full" (Meo, 2010).

\subsubsection{More Comprehensive Data}

Many researchers, dating as far back as John Collier in his seminal book Visual Anthropology, noted that participatory visual methods improved the quality of data that could be collected during the research process. Specifically, he noted that the use of photos "elicited longer and more comprehensive interviews but at the same time helped subjects overcome the fatigue and repetition of conventional 
interviews...This was its compelling effect upon the informant, its ability to prod latent memory, to stimulate and release emotional statements about the informant's life..." (Collier \& Collier, 1986).

\subsubsection{Better Access}

As with all social science research, access to the physical and social context the researcher wishes to study is always a consideration. Participatory visual researchers claimed that treating their participants as experts in their own right overcame access issues because they did not need to "adopt any role to legitimize or justify their presence, since they are members of the community, not outsiders" (Wang, Burris, \& Ping, 1996). In her research, Wang noted that "the significance of this advantage should not be underestimated, since access is often one of the most difficult aspects confronting photographers" (Wang et al., 1996).

In studies that were less participatory in nature, researchers noted that visual methods promoted rapport between researcher and subject (Meo, 2010), helping to establish "trusting relationships among researchers, practitioners, and members of underserved communities" (Catalani \& Minkler, 2010). These benefits, researchers claim, open the door to better access to research participants.

\subsubsection{More Accurate Data}

The claim that visual methods provide better data was common, although a definition for better was elusive. Hartel and Thomson's examination of information spaces in the hobby of gourmet cooking, and her subsequent reflection on non-participatory visual photographic methods supported the idea that better meant more complete and more accurate in situations where data can be hard to obtain. For example, Hartel and Thomson argue that photographic methods are useful in "busy research environments in which the fieldworker is not able to observe everything of relevance in a limited timeframe" (J. K. Hartel \& Thomson, 2011). In such cases, visual methods help the researcher establish "scale, size, and layout, among other things, and to survey, quantify, characterize, and typologize the artifacts therein" (J. K. Hartel \& Thomson, 2011). Practitioners also noted repeatedly that photo methods can assist with data triangulation (Bishop, 2006; Catalani \& Minkler, 2010; J. K. Hartel \& Thomson, 2011).

\subsubsection{Etic and Emic Perspectives}

One of the significant differences between participatory and non-participatory visual research is the point of view from which the data is collected. Coined by linguist Kenneth Pike, the term etic refers to perspectives that reflect "phenomenal distinctions judged appropriate by the community of scientific observers" (Harris, 575). By contrast, the term emic refers to "systems whose phenomenal distinctions or "things" are built up out of contrasts and discriminations significant, meaningful, real, accurate, or in some other fashion regarded as appropriate by the actors themselves" (Harris, 571). By extension, the term etic is used in this paper to refer to studying phenomena from the outside-in or from the perspective of the researcher. Etic research is described as "non-participatory". Emic refers to examining phenomena from the inside-out, or from the perspective of the participants themselves. Emic research is described as participatory.

While some researchers made explicit attempts to discuss the importance of perspective in their studies, it was often overlooked or assumed in explanations. Yet perspective is crucial to interpreting the data, and it permeates every aspect of research design when using visual methods. Some researchers noted that non-participatory research methods are well positioned to "situate the [researcher's] own observation at the heart of the research process, promoting an active engagement with the subject studied" (Hall, 2009). As Singhal explains, however, participatory methods mean "working with and by the people, as opposed to working on or working for the people" (Singhal et al., 2007). Participatory 
methods, therefore, tend to shift the research perspective toward the emic, or the view belonging to or originating from the participants themselves.

\subsubsection{Support Inductive Methodologies}

Although photo methods are not new to qualitative research, they have been slow to gain acceptance, and many researchers reported that their research design changed as a result of feedback during the data collection process. Catalani and Minkler noted that "photovoice discussions varied in frequency and in style," and that "the more participatory projects tended to engage community photographers in a cycle of photography or documentation and discussion over several months" (Catalani \& Minkler, 2010). Hall supported this finding, suggesting that "in many cases, researchers have found the process to be iterative and fluctuating as the research develops" (Hall, 2009). The flexible, reflexive nature of the method supports similar methodologies, particularly exploratory research designed to describe social phenomena that are not yet well understood.

\subsubsection{Diffusion of Findings}

Most scientific research is communicated to specific stakeholder groups through text. Visual methods, however, are uniquely positioned not only to "arouse interest and curiosity within the larger population" (Wang et al., 1996), but also to support new, creative methods of reporting, including "photo-essays, exhibitions, mixed media or experimental texts [which] look very different from the academic texts ... [we] are familiar with" (Hall, 2009).

\subsubsection{Empowerment}

One of the primary tenets of participatory visual methods is the potential for the method to shift the balance of power from researcher to participant (Wang \& Burris, 1997). Based on Freire's (Freire, 2000) work and Feminist methodology, Wang explains that putting cameras in the hands of research subjects mobilizes them to "record and catalyze" their communities, "rather than stand as passive subjects of other people's intentions and images" (Wang \& Burris, 1997). Catalani reports that, in particular, "two iterative processes...facilitated empowerment: documenting community strengths and concerns using photography and engaging in critical dialogue with other community members" (Catalani \& Minkler, 2010).

\subsubsection{Modes of Expression}

Not surprisingly, non-textual and non-verbal methods of communication invite non-textual and nonverbal modes of expression, which, Clark explains, "may be in contrast to the dominant written discourses of report-writing and assessment" (Clark, 2011). Bishop tells us that "visual methods begin to honor graphic expression as an alternative form of knowing" (Bishop, 2006). This is particularly wellsuited to research with groups of differing ages and abilities. For example, "drawing is particularly wellsuited for the young adolescent who, grappling with tremendous developmental changes and the emergence of life's quintessential questions, at times lacks the language to describe the increasingly sophisticated understandings that emerge at this stage of life" (Bishop, 2006). Visual methods, therefore, have the potential to bridge gaps where language ability may be a barrier, for example, among the very young, the disabled, or among populations where the researcher and the participant do not share a common language.

\subsubsection{Sensitive Issues}

An interesting advantage of image based research related to modes of expression is the idea that visual images in research may allow "participants to introduce new and possibly contentious topics in ways that are not possible in a purely verbal exchange" (Croghan, Griffin, Hunter, \& Phoenix, 2008). 
Researchers have noted that the use of images allowed researchers to discuss "aspects of experience that do not fit with cultural stereotypes... [and] positions that are usually silent" (Croghan et al., 2008).

\subsubsection{Diverse populations}

Also related to modes of expression, visual methods have found successful applications working among diverse populations, including homeless people, immigrant women, indigenous groups, and older individuals (Novek, Morris-Oswald, \& Menec, 2012). It has also been used with adults and children (Clark, 2011), young people (Croghan et al., 2008), post-secondary students (Keller, 2012), teachers (Stockall \& Davis, 2011), and rural women (Willson, Green, Haworth-Brockman, \& Beck, 2006). Image or art-based visual methods have shown particular promise among populations requiring or experiencing therapeutic interventions (Pink et al., 2011).

\section{Limitations}

\subsection{Disadvantages of Visual Methods}

While benefits associated with visual research methods exist, Packard noted that "these methods [are] far from perfect, with much theoretical and empirical work still to be done" (Packard, 2008). Success ultimately depends on the skill of the researcher and the implementation of the research design. For that reason, consideration should also be given to the areas where visual methods present unique challenges. The primary drawback of visual methods, as Hall explains, is that "photographic surveys will inevitably be partial and will represent the choices made by those responsible for their construction and the constraints they were working within" (Hall, 2009). Although this criticism is something to be aware of, it should be noted that this is also a criticism of a great many other, more traditional qualitative research methods.

\subsubsection{Requires more Resources}

Visual methods require more resources. Visual data can often be easily collected in great quantities, but it is complex, difficult and time consuming to analyze. It also requires more financial commitment, planning, and technology. Meo described her experiences succinctly: "in practical terms, [photointerviews] were more expensive and time consuming than traditional ones. They were also more challenging and demanding... [Photo-interviews] demanded more time before, during, and after the interviews" (Meo, 2010). While this generally appears to be true, Keller noted that with the proliferation of digital technologies and real-time sharing of images, "some of the technical and organizational disadvantages reported in other studies," are disappearing, (Keller, 2012). Packard also indicated that "the cost of conducting such research has fallen dramatically in the past decade" (Packard, 2008).

\subsubsection{Limited Availability}

In cases where researchers are attempting to examine historical or salvage photographs, practical considerations of availability must be addressed. Arreola and Burkhart identified "perceived limited extent and availability of historic imagery" (Arreola \& Burkhart, 2010) as a barrier to use of this method. Sometimes the historical images the researcher would like to use are simply unavailable. Additionally, Pollak (2015) found that personal photographic collections among her rural population had been compromised by both poor access to the technology due to prohibitive costs, and by house fires which were a common occurrence in past decades. Further, identification of and access to large or significant private collections can be difficult (Arreola \& Burkhart, 2010). 


\subsubsection{Recruitment}

Despite the many advantages to participatory visual methods, researchers "continue to grapple with the ideal of community participation in all of the stages of the research process" (Catalani \& Minkler, 2010). Researchers also noted the tendency of participants opting not to complete the process once recruited (for example, accepting cameras, but not returning them).

\subsubsection{Validity}

Bishop addressed the issue of validity of data obtained through visual methods, which can potentially be subjected to "over-analyzing, misinterpreting and/or incorrectly attributing emotions or actions to certain depictions" (Bishop, 2006). Researchers suggested that visual methods were ideal in mixedmethod studies (often including interview protocols) which help triangulate data and overcome validity issues.

\subsubsection{Objectification and False Neutrality}

A common criticism leveled against visual methods suggests that it tends to "exoticize or objectify others of various kinds" (Buckingham, 2009) by representing a falsely neutral reflection of reality. No doubt, visual methods of research are highly contextual. Researchers must be aware that choosing a particular research method is an inherently political act (Erim, 2011) and make a conscious effort to identify the "lines of power and knowledge" (Croghan et al., 2008) at play in their particular context.

\subsubsection{Power and Control}

No matter how ideal participatory visual methods are for distributing responsibility, power dynamics are inherently part of the context, and control of resources may inadvertently reinforce social inequalities. Distributing power and voice to participants by asking them to take photos is noble, but the researcher still needs to address issues of power and control associated with, for example, finance, authority, and editorial rights that determine ownership, evaluation, and inclusion or exclusion. Recruitment, often limited by knowledge and access, further enforce hidden issues of power and control.

Despite efforts to cast the net as widely as possible, issues around power brokerage nevertheless arise over matters as simple as instructions. Packard explains that "in order to equalize power relationships in a project, technical competencies must be similar. An unequal power dynamic is immediately and irrevocably established the moment the researcher must instruct a participant on how to operate a piece of equipment" (Packard, 2008). Other researchers have called attention to the role that the researcher plays in instructing the participants on what to photograph as well. Wang points out that although participatory visual methods "implicitly assume that the community priorities will be communicated to policy makers who have the influence and control to bring about change," going through the hierarchy sometimes inadvertently reinforces the power/victim roles (Wang \& RedwoodJones, 2001).

\section{Ethical Considerations}

Ethics is an issue that affects both participants and researchers in equal measure in all research involving human subjects. In his chapter discussing ethics in field research, Thrift points out how "agonizing situations" may arise for the researcher that "will not be resolved but rather will rumble on uneasily and ambiguously through the rest of your life: did I do the right thing? You will never have the satisfaction of knowing that you did the right thing because no easy definition of 'right' exists" (Thrift, 2003). In terms of this review of the literature describing visual research, discussions of ethics provided in many of the 
studies examined are best described as incomplete. At worst, researchers failed to address the issue of ethics at all, at least in their writeups.

The most comprehensive discussions of ethics specifically in visual research examined included those by Wang \& Redwood Jones (2001) (including a list of ethical best practices) and Barrett (2004). There is agreement, however, that photography in particular is an inherently political act, and individuals who participate may face uncertain or unpredictable outcomes, especially when combined with audiorecorded interviews. Discussions of ethics focused on how decisions made by the researcher affected participants, with very few reflecting (on) the outcomes for the researcher as described by Thrift above. Following are some of the ethical concerns that emerged from the review of the literature.

\subsection{Legal Risks}

Researchers identified legal risks to participants that emerged from visual study designs. This can include situations where identification of individual participants might place them in a false light (Wang \& Redwood-Jones, 2001) or where participants' input may be valuable specifically because they participate in illegal activities (Barrett, 2004). Legal issues can also involve ownership and copyright issues for the photographs that are taken, and protecting individuals from use of their images for commercial benefit (Wang \& Redwood-Jones, 2001).

\subsection{Safety Risks}

Because visual methods of research may be conducted in a wide array of geo-political contexts, Wang admonishes researchers to "hold the safety of the participants above the spontaneity or power of the image" (Wang \& Redwood-Jones, 2001). Although permissions may be obtained, "the camera is not a shield, and participants must be aware of their surroundings and potential dangers at all times" (Wang \& Redwood-Jones, 2001). Barrett also notes that occasions may arise where, even with permission of the participant, it may be prudent not to use certain photographs due to the potential of repercussions at some future time (Wang \& Redwood-Jones, 2001).

\subsection{Identification Risks}

As is standard with all research protocols involving human subjects, both participatory and nonparticipatory visual methods require consideration of whether and how to preserve the anonymity of all parties involved. Anonymity protects both photographers and the people photographed from intrusions into personal space (J. K. Hartel \& Thomson, 2011) and "disclosure of embarrassing facts about individuals" (Wang \& Redwood-Jones, 2001) that may be apparent from inclusion in or exclusion from selected contexts.

\section{Conclusion and Recommendations}

Innovation is bound to present challenges for LIS researchers who venture away from the familiar and borrow from interdisciplinary methodological toolboxes to better illuminate their own domains. Nevertheless, the footwork involved in sorting out terminology and best practices builds a foundation upon which more nuanced exploration and development can happen in the future. Although not wholeheartedly embraced as of yet, both participatory and non-participatory visual methods certainly have a future place in LIS research. They are well suited to an interdisciplinary field like LIS, and in particular, to qualitative researchers who are comfortable - even excited about - exploring information worlds filled with vagueness, contradiction, fluidity and movement. Researchers who take up the call are encouraged to fill in the many gaps between current usage of this methodology and optimal usage, and 
to deepen the methodological, theoretical and ethical conversations specifically as they relate to using this methodology in LIS research. Though beyond the scope of this article, further exploration of how visual methods can be used not only as a tool for gathering data, but also as a tool for knowledge mobilization, translation and diffusion are also exciting, particularly as they relate to the fields of performance art, information visualization and digital humanities.

\section{Acknowledgements}

An earlier version of this material won the annual ALISE/Proquest Methodology award and was presented at the 2014 Association for Library and Information Science Education conference held in Philadelphia, PA.

Special thanks to the editor and reviewers of this paper for the insightful comments and feedback that encouraged me to stretch my skill and thinking, and improved this paper in important and gratifying ways. 


\section{References}

Adams, A., \& Turnage, W. A. (2006). Sierra Nevada: The John Muir Trail. New York, NY: Little, Brown and Co.

Allen, L. (2008). Young people's "agency" in sexuality research using visual methods. Journal of Youth Studies, 11(6), 565-577. https://doi.org/10.1080/13676260802225744

Arreola, D. D., \& Burkhart, N. (2010). Photographic postcards and visual urban landscape. Urban Geography, 31(7), 885-904. https://doi.org/10.2747/0272-3638.31.7.885

Banks, M. (2001). Visual methods in social research (2nd ed.). Thousand Oaks, CA, US: SAGE Publications, Inc.

Banks, M., \& Ruby, J. (Eds.). (2011). Made to be seen: Perspectives on the history of visual anthropology. Chicago : University of Chicago Press,.

Barrett, D. (2004). Photo-documenting the needle exchange: Methods and ethics. Visual Studies, 19(2), 145-149. https://doi.org/10.1080/1472586043000301647

Bishop, P. A. (2006). The promise of drawing as visual method in middle grades research. Middle Grades Research Journal, 1(2), 33-46.

Buckingham, D. (2009). "Creative" visual methods in media research: Possibilities, problems and proposals. Media, Culture \& Society, 31(4), 633-652. https://doi.org/10.1177/0163443709335280

Case, D. O. (2007). Looking for information: A survey of research on information seeking, needs, and behavior (2nd ed.). San Diego, CA: Elsevier/Academic Press.

Catalani, C., \& Minkler, M. (2010). Photovoice: A review of the literature in health and public health. Health Education \& Behavior, 37(3), 424-451. https://doi.org/10.1177/1090198109342084

Clark, A. (2011). Breaking methodological boundaries? Exploring visual, participatory methods with adults and young children. European Early Childhood Education Research Journal, 19(3), 321330. https://doi.org/10.1080/1350293X.2011.597964

Collier, J. (1967). Visual anthropology: Photography as a research method. New York : Holt, Rinehart and Winston,.

Collier, J., \& Collier, M. (1986). Visual anthropology: Photography as a research method. Albuquerque, NM: University of New Mexico Press. 
Croghan, R., Griffin, C., Hunter, J., \& Phoenix, A. (2008). Young people's constructions of self: Notes on the use and analysis of the photo-elicitation methods. International Journal of Social Research Methodology, 11(4), 345-356. https://doi.org/10.1080/13645570701605707

Cross, K., Kabel, A., \& Lysack, C. (2006). Images of self and spinal cord injury: Exploring drawing as a visual method in disability research. Visual Studies, 21(2), 183-193. https://doi.org/10.1080/14725860600945044

Denham, P. (1993). Nine-to fourteen-year-old children's conception of computers using drawings. Behaviour \& Information Technology, 12(6), 346-358.

Documentary Educational Resources. (2016). Films about Jean Rouch. Retrieved November 16, 2016, from http://der.org/jean-rouch/content/index.php?id=about_filmsabout

Documentary Education Resources. (2016). Jean Rouch: A Tribute. Retrieved November 16, 2016, from http://der.org/jean-rouch/content/index.php?id=about_filmography

Eaton, M. (Ed.). (1979). Anthropology, reality, cinema: the films of Jean Rouch. London: British Film Institute.

Erim, D. (2011). Researching the middle: Visual ethnography as an experimental, innovative method. Ileti-S-Im, (15), 9-27.

Foster, N. F., \& Gibbons, S. (2007). Studying students: The undergraduate research project at the University of Rochester. Chicago, Illinois: ALA Editions. Retrieved from http://www.ala.org/acrl/sites/ala.org.acrl/files/content/publications/booksanddigitalresources/ digital/Foster-Gibbons_cmpd.pdf

Freire, P. (1993). Pedagogy of the city. New York, NY: Continuum.

Freire, P. (2000). Pedagogy of the oppressed. New York, NY: Continuum.

Freire, P., \& Faundez, A. (1989). Learning to question: A pedagogy of liberation. New York, NY: Continuum.

Freire, P., \& Freire, A. M. A. (1994). Pedagogy of hope: Reliving pedagogy of the oppressed. New York, NY: Continuum.

Freire, P., \& Freire, A. M. A. (1997). Pedagogy of the heart. New York, NY: Continuum.

Gabridge, T., Gaskell, M., \& Stout, A. (2008). Information seeking through students' eyes: The MIT photo diary study. College \& Research Libraries, 69(6), 510-522.

Haberl, V., \& Wortman, B. (2012). Getting the picture: Interviews and photo elicitation at Edmonton Public Library. Libres: Library \& Information Science Research Electronic Journal, 22(2), 1-20. 
Hall, T. (2009). The camera never lies? Photographic research methods in human geography. Journal of Geography in Higher Education, 33(3), 453-462. https://doi.org/10.1080/03098260902734992

Harper, D. A. (1993). On the authority of the image: Visual methods at the crossroads. In N. K. Denzin \& Y. S. Lincoln (Eds.), Handbook of Qualitative Research. Newbury Park, Calif.: SAGE Publications.

Hartel, J. (2014). An arts-informed study of information using the draw-and-write technique. Journal of the Association for Information Science \& Technology, 65(7), 1349-1367. https://doi.org/10.1002/asi.23121

Hartel, J. K. (2006). Information activities and resources in an episode of gourmet cooking. Information Research, 12(1).

Hartel, J. K., \& Thomson, L. (2011). Visual approaches and photography for the study of immediate information space. Journal of the American Society for Information Science \& Technology, 62(11), 2214-2224. https://doi.org/10.1002/asi.21618

Hartel, J., Lundh, A., Sonnenwald, D., \& Foster, N. F. (2012). State of the art/science: Visual methods and information behavior research. Proceedings of the American Society for Information Science and Technology, 49(1), 1-4. https://doi.org/10.1002/meet.14504901009

Horn, J. (1998). Qualitative research literature: A bibliographic essay. Library Trends, 46(4), 602-615.

Huck, J., Al, R., \& Rathi, D. (2011). Finding KM solutions for a volunteer-based non-profit organization. Vine: The Journal of Information and Knowledge Management Systems, 41(1), 26-40. https://doi.org/10.1108/03055721111115539

Julien, H., Given, L. M., \& Opryshko, A. (2013). Photovoice: A promising method for studies of individuals' information practices. Library and Information Science Research, 35(4), 257-263. https://doi.org/10.1016/j.lisr.2013.04.004

Julien, H., \& Hoffman, C. (2008). Canada's public libraries and information literacy training. Feliciter, 54(2), 74-77.

Keller, A. (2012). In print or on screen? Investigating the reading habits of undergraduate students using photo-diaries and photo-interviews. Libri: International Journal of Libraries \& Information Services, 62(1), 1-18. https://doi.org/10.1515/libri-2012-0001

Kuhn, A. (2007). Photography and cultural memory: A methodological exploration. Visual Studies, 22(3), 283-292. https://doi.org/10.1080/14725860701657175

Lange, D. (1969). American exodus: A record of human erosion in the Thirties. New Haven, CT: Yale U. P.

Mair, M., \& Kierans, C. (2007). Descriptions as data: Developing techniques to elicit descriptive materials in social research. Visual Studies, 22(2), 120-136. https://doi.org/10.1080/14725860701507057

Marshall, A., Burns, V., \& Briden, J. (2007). Know your students. Library Journal, 132(18), 26-29. 
McKenzie, P. J., \& Davies, E. (2012). Genre systems and "keeping track" in everyday life. Archival Science, 12(4), 437-460. https://doi.org/10.1007/s10502-012-9174-5

Meo, A. I. (2010). Picturing students' habitus: The advantages and limitations of photo-elicitation interviewing in a qualitative study in the city of Buenos Aires. International Journal of Qualitative Methods, 9(2), 149-171.

Moore, G., Croxford, B., Adams, M., Refaee, M., Cox, T., \& Sharples, S. (2008). The photo-survey research method: Capturing life in the city. Visual Studies, 23(1), 50-62. https://doi.org/10.1080/14725860801908536

Novek, S., Morris-Oswald, T., \& Menec, V. (2012). Using photovoice with older adults: Some methodological strengths and issues. Ageing \& Society, 32(3), 451-470. https://doi.org/10.1017/S0144686X11000377

Okamoto, T., Fujihara, T., Kato, J., Kosugi, K., Nakazato, N., Hayashi, Y., ... Nonami, H. (2006). Measuring social stereotypes with the photo projective method. Social Behavior \& Personality: An International Journal, 34(3), 319-331.

Packard, J. (2008). "I'm gonna show you what it's really like out here": The power and limitation of participatory visual methods. Visual Studies, 23(1), 63-77. https://doi.org/10.1080/14725860801908544

Pauwels, L. (2010). Visual Sociology Reframed: An Analytical Synthesis and Discussion of Visual Methods in Social and Cultural Research. Sociological Methods \& Research, 38(4), 545-581. https://doi.org/10.1177/0049124110366233

Pauwels, L. (2015). Reframing visual social science: Towards a more visual sociology and anthropology. London, UK: Cambridge University Press.

Perlmutter, D. D. (1994). Visual historical methods. Historical Methods, 27(4), 167.

Pink, S., Hogan, S., \& Bird, J. (2011). Intersections and inroads: Art therapy's contribution to visual methods. International Journal of Art Therapy: Inscape, 16(1), 14-19. https://doi.org/10.1080/17454832.2011.570273

Pollak, A. (2015, April). Words to live by: How experience shapes our information world at work, play and in everyday life. University of Western Ontario. Retrieved from http://ir.lib.uwo.ca/etd/2722

Prosser, J. (2007). Visual methods and the visual culture of schools. Visual Studies, 22(1), 13-30. https://doi.org/10.1080/14725860601167143

Prosser, J., \& Loxley, A. (2008). Introducing Visual Methods (Working Paper). NCRM. Retrieved from http://eprints.ncrm.ac.uk/420/ 
Rose, G. (2012). Visual methodologies : an introduction to researching with visual materials /(3rd ed.). London; SAGE,.

Rouch, J., \& Feld, S. (2003). Cine-Ethnography (annotated edition edition). Minneapolis: Univ Of Minnesota Press.

Salgado, S. (1986). Other Americas. New York, NY: Pantheon Books.

Singhal, A., Harter, L. M., Chitnis, K., \& Sharma, D. (2007). Participatory photography as theory, method and praxis: Analyzing an entertainment-education project in India. Critical Arts: A South-North Journal of Cultural \& Media Studies, 21(1), 212-227. https://doi.org/10.1080/02560040701398897

Smith, T. (2007). Repeat photography as a method in visual anthropology. Visual Anthropology, 20(2), 179-200. https://doi.org/10.1080/08949460601152815

Sonnenwald, D. H., Wildemuth, B. S., \& Harmon, G. L. (2001). A Research Method to Investigate Information Seeking using the Concept of Information Horizons: An Example from a Study of Lower Socio-economic Students' Information Seeking Behavior. The New Review of Information Behavior Research, 2, 65-86.

Stockall, N., \& Davis, S. (2011). Uncovering pre-service teacher beliefs about young children: A photographic elicitation methodology. Issues in Educational Research, 21(2), 192-209.

Stoller, P. (1992). The cinematic griot : the ethnography of Jean Rouch /. Chicago : University of Chicago Press,.

Thrift, N. (2003). Practicing Ethics. In M. Pryke, G. Rose, \& S. Whatmore (Eds.), Using Social Theory Thinking Through Research (pp. 106-121). London; SAGE in association with the Open University,

Umoquit, M. J., Tso, P., Burchett, H. E., \& Dobrow, M. J. (2011). A multidisciplinary systematic review of the use of diagrams as a means of collecting data from research subjects: Application, benefits and recommendations. BMC Medical Research Methodology, 11, 11. https://doi.org/10.1186/1471-2288-11-11

Wagner, J. C. (Ed.). (1979). Images of information: Still photography in the social sciences. Beverly Hills: Sage Publications.

Wang, C., \& Burris, M. A. (1997). Photovoice: Concept, methodology, and use for participatory needs assessment. Health Education \& Behavior, 24(3), 369-387. https://doi.org/10.1177/109019819702400309

Wang, C., Burris, M. A., \& Ping, X. Y. (1996). Chinese village women as visual anthropologists: A participatory approach to reaching policymakers. Social Science \& Medicine, 42(10), 1391-1400. https://doi.org/10.1016/0277-9536(95)00287-1 
Wang, C., \& Redwood-Jones, Y. (2001). Photovoice ethics: Perspectives from Flint photovoice. Health Education \& Behavior, 28(5), 560-572. https://doi.org/10.1177/109019810102800504

Weber, S. J. (1993). Using Visual Methods in Research. In N. K. Denzin \& Y. S. Lincoln (Eds.), Handbook of Qualitative Research. Newbury Park, Calif.: SAGE Publications.

Weber, S. J., \& Mitchell, C. (2016). IIRC- reloaded: Visual methodologies. Retrieved November 14, 2016, from http://iirc.mcgill.ca/txp/?s=Methodology\&c=Visual\%20methodologies

Weingand, D. E. (1993). Grounded theory and qualitative methodology. presented at the 1992 IFLA Conference. IFLA Journal, 19(1), 17-26.

Wilder, K. E. (2009). Photography and the art of science. Visual Studies, 24(2), 163-168. https://doi.org/10.1080/14725860903106161

Willson, K., Green, K., Haworth-Brockman, M., \& Beck, R. R. (2006). Looking out: Prairie women use photovoice methods to fight poverty. Canadian Woman Studies, 25(3), 160-166. 